Article

\title{
Regional Convergence and Sustainable Development in China
}

\author{
Fang Yang ${ }^{1,2}$, Shiying Pan $^{3}$ and Xin Yao ${ }^{3,4, *}$ \\ 1 Collaborative Innovation Center for Peaceful Development of Cross-Strait Relations, Xiamen University, \\ Xiamen 361005, China; yangfang@xmu.edu.cn \\ 2 School of Economics, Xiamen University, Xiamen 361005, China \\ 3 China Center for Energy Economics Research, School of Economics, Xiamen University, \\ Xiamen 361005, China; 31320131152237@stu.xmu.edu.cn \\ 4 Collaborative Innovation Center for Energy Economics and Energy Policy, Xiamen University, \\ Xiamen 361005, China \\ * Correspondence: yaoxin@xmu.edu.cn or lyhneyao@hotmail.com; Tel.: +86-592-218-6076; \\ Fax: +86-592-218-6075
}

Academic Editors: Yongrok Choi, Malin Song and Seunghwan Myeong Received: 30 November 2015; Accepted: 21 January 2016; Published: 28 January 2016

\begin{abstract}
Based on the convergence theory of economic growth, this paper extends this concept to the human development index and carries out an empirical analysis of regional development in China between 1997 and 2006. Our research shows that the conditional convergence has been identified. Investment in fixed assets, government expenditure on education, health and infrastructure construction have positive effects on regional convergence of social development. Population weighted analysis of human development index provides support for weak convergence amongst provinces. Analysis of dynamics of regional distribution reveals the club convergence, which indicate two different convergence states. Central China is in the shade and lags behind, giving rise to the so-called "central downfall". To solve this problem, the "Rise of Central China" Plan is necessary to promote the connection between coastal and inland regions of China and reduce the regional development gap.
\end{abstract}

Keywords: social development; human development index; convergence; inequality

\section{Introduction}

In recent years, with China's rapid economic growth, issues of regional disparity in China have attracted the attention of scholars at home and abroad and been discussed in detail. However, previous research mainly focused on economic growth, and the indicator commonly used was income level, which is a great limitation for measuring levels of development of different regions. For a country or region, the ultimate goal of social development is common development of all members and enhancement of human capacity. This "capacity" includes: capacity to live a healthy and long life; capacity to have access to culture and technology and share the fruits of social civilization, and capacity to lift themselves out of poverty and improve the standard of living (UNDP, 2005) [1]. Economic development is the foundation of social development. A country can maintain rapid economic growth in the short term, but it does not mean that the social development indicators also improve. In the long run, economic growth at the cost of ignoring social development is unsustainable. As a more environmentally-friendly way to enhance human well-being. Mikkelson [2] tested the merits of equality through analysis of a few key national economic and ecological variables across time and space. In addition, the results confirmed the hypothesis that equality did far less harm to the ecosystem than growth did. 
The human development index (HDI), introduced by the United Nations Development Program (UNDP) in 1990, is a comprehensive indicator for measuring social development of different countries or regions, reflecting three major dimensions of human development: income, health and education. Since reform and opening up, China has made significant progress in economy, education and health, but the fact of regional disparity should not be ignored. Regional differences in human development limit the potential for sustainable development in China. China is in urgent need to cope with the challenge of social justice, that is, how to achieve equal opportunities and capabilities for its huge population. This not only coincides with the current goal of "building a harmonious society", but also becomes an important part of the Millennium Development Goals (MDGs).

Since the middle of the 1990s, many domestic scholars have used the human development index (HDI) to undertake a study on differences in social development of different regions in China, and found the regional imbalance of social development. That is, the Eastern China develops much better than the Western and Central China. Li, et al. [3] analyzed the human development index of China's provinces in 1999, and found that the differences between various provinces was narrowing. Tan and Luo [4] thought, in spite of the shrinking gap between provinces, at the same time, there has been a polarization. That is, the pattern of high east and low west is strengthening. Song [5] estimated the HDI gap between the urban and rural areas. Results showed that the urban-rural income gap was the highest. Inequality among countries was not taken into consideration in most studies on HDI. Grimm [6] proposed a methodology where HDI could be computed for quintiles of the income distribution. By this method, human development levels of poor and rich countries could be compared. Harttgen and Klasen [7] provided a method for estimating HDI at the household level with data of 15 developing countries. This method could be used to analyze human development and inequality across population subgroups. Eric [8] analyzed 155 countries and concluded that 42 countries could not achieve unsustainable development because of low HDI.

Since the concept was put forward, the index was extended and developed constantly. The United Nations introduced the new HDI in 2010. Felice and Vasta [9] discussed and presents estimate of the new HDI to analyze the convergence in Italy from 1871-2007. They found different parts of Italy began to convergence from the late nineteenth century to 1970, but stopped in the last decades of the twentieth century. The Human Sustainable Development Index (HSDI) which adds the environmental dimension is a way to amend the traditional HDI. It was found by Bravo [10]. Although the HSDI was a step ahead compared to HDI, it was still insufficient when representing the environmental sustainability. Hou et al. [11] put forward a different way to construct HDI in terms of capturing the pure flow of human development in the areas of material well-being, education and health. Ravallion [12] put forward an alternative index which had less troubling tradeoffs while imperfect substitution was still allowed.

Scholars are also interested in the relationship between HDI and other variables. Samuel [13] analyzed the association between worldwide prevalence of physical inactivity with development level of each country. They found that HDI was positively correlated with prevalence of physical inactivity. Li et al. [14] studies HDI of 141 countries and found it was inversely correlated with HIV / AIDS mortality, prevalence, and incidence rates. Yekeen [15] used HDI to measure deprivations among urban households in Minna, Nigeria. Freddie [16] divided HDI into four levels (low, medium, high, and very high) to investigate global cancer transitions. Nadia [17] used a panel cointegration and error correction model to analyze the causality relationship between energy consumption as well as electricity consumption and HDI. They found little relationship between in the short term, but a negative cointegration relationship between energy consumption and the HDI, as well as a positive cointegration relationship between electricity consumption and HDI.

Yang et al. [18,19] used the method of principal component analysis based on the covariance matrix to analyze human development in all regions in China since 1990, and results showed that regional disparities in economy, education, health and other aspects were obvious. The income and wage inequality are the focus of most scholars, such as Hu [20], Qin et al. [21], Gustafsson [22], 
Appleton et al. [23]. Many researchers also pay attention to regional disparity and its influencing factors. Naranpanawa [24] found that the rich and fast-growing middle-income states would benefit from trade liberalization, while it had a marginal or negative influence on the poor states in the short run, by using a multiregional Computable General Equilibrium (CGE) model of Indian. Duan [25] found that population mobility of China also had a significant impact on the tendency and structure of regional disparity, and the regional disparity was enlarged by the population mobility since 1978 . Chirila [26] investigated how the regional disparities were influenced by economic and financial crisis in Romania and European Union. Song [27] analyzed intercity regional disparity in China and presented evidence on the evolution and magnitude of regional disparities. He also estimated how regional per capita income (PCI) and per capita gross domestic product (PCGDP) responded to specific regional and national policies. By conducting counterfactual experiments, Liu [28] assessed the influences of technological changes on China's regional disparities. The results generally suggested that China's regional disparities were enlarged by overall technological change between 1987 and 2000 . Literatures both at home and abroad on regional disparities from an empirical perspective adopted two ways: one was to validate the convergence hypothesis (Barro [29], Mankiw [30].); the other was to measure the inequality and analyze its dynamic changes (Quah [31], Sala-i-Martin [32]). Goals of those two methods were consistent, which were to test whether the income distribution of developed and underdeveloped regions was equal or polarized. Most of those studies concentrated on the indicator of income, but few scholars used other welfare indicators to analyze the social development in China. With the improvement of technology and communication, compared with researches on income gap, analysis of disparities in education, health care and others is also of practical significance. Therefore, based on the convergence theory, we use abovementioned methods to analyze regional disparities in social development and compensate the shortage of existing literature.

Almost every country takes sustainable development as its ultimate goal of development. The existing literatures usually focus more on how to achieve sustainable development. Cristina [33] analyzed the steps needed to progress towards a valid sustainable development. Cornescu [34] selected the indicators of sustainable development according to the characteristic of each country to extend the sustainability assessment framework. Nuzir [35] studied the role of education facility in sustainable urban development by estimating its influence on the development of economy, society and environment. Radjiyev et al. [36] found the ergonomics could have an impact on sustainable development. Based on the PCA, Bolcárová [37] aimed to create an aggregated index of sustainable development from SDIs for $27 \mathrm{EU}$ countries. This new aggregated index was related with economic growth and they found that the correlation between the economic growth and aggregated SD index was negative in most of the 27 EU countries. Can every country achieve it? Chansarn [38] used the Data Envelopment Analysis (DEA) to study the sustainable human development of 115 high and middle income countries which were divided into three groups according to their income levels. The findings revealed that certain countries could realize the sustainable human development while other countries could not. Elizabeth A. Stanton [39] explored the dimensions of equity/sustainability linkage from the perspective of public goods analysis. Qin [40] pointed out that in the process of social transformation, sustainable development in China faced new challenges and advised several aspects including environmental law, principle of prevention, environmental impact and risk assessment system and green tax system to better respond to these challenges. Corina Rădulescu et al. [41] proposed a conceptual integrated model which promoted a balance of interaction between systems-economy, human, environment and technology—in a dynamic, flexible and functional process, in order to promote the sustainable development in Maramures County.

The main structure of this paper is as follows: in Section 2, we use the convergence theory to analyze differences in the human development index after a brief review of literature; Section 3 makes an empirical study of convergence of social development of China's 31 provinces and analysis of influencing factors of social development through the method of $\beta$ and $\sigma$ convergence; in Section 4 , 
regional inequality in social development of China is measured, and its dynamic changes are further discussed and explored; Section 5 presents corresponding conclusions and policy recommendations.

\section{Convergence of the Human Development Index (HDI)}

\subsection{Theories and Methods of Convergence}

The convergence hypothesis is derived from the neo-classical growth theory which emphasizes the effect of capital investment on economic growth. A production function with constant returns to scale and the diminishing returns of capital is assumed. That is, the economy with lower level of initial productivity enjoys a higher rate of growth in productivity and as such will catch up with the more developed economies. Validation of the convergence hypothesis is of great theoretical and practical significance. It can not only test neo-classical growth theory in some areas, but also analyze its influencing factors and internal development mechanism.

To explain the process of catching up among countries or regions, Barro [42], Barro and Sala-I-Martin [43] proposed two methods to validate the convergence hypothesis, namely the $\beta$-convergence method and $\sigma$-convergence method. The former one mainly concentrates on the difference in growth rate among countries or regions while the latter one focuses on distribution difference in growth rate. In addition, the $\beta$-convergence method can be classified into the absolute convergence and conditional convergence method. The absolute convergence method assumes that conditions in all regions are the same except the initial capital. That is to say, not only all regions can reach the steady state, with similar technological advances and policies, but also the long-term equilibrium levels of different regions are the same. The conditional convergence assumes different speeds of technological progress or different levels of output per capita in different regions. Economic growth depends on the initial level of income, but is restricted by other factors, such as savings, population growth rate and environmental policies. When it comes to the conditional convergence, the convergence path may be different in different countries or regions, but after introducing some key control variables, all countries eventually converge to the same steady-state.

In addition, some scholars further extended the concept of convergence and proposed the "convergence clubs". The "convergence clubs" emphasizes that due to differences in initial state, different economies can lead to different kinds of equilibrium, which is different from the concept of conditional convergence. Hence, underdeveloped countries (or regions) and developed countries (or regions) have their own conditional convergences, but the differences between the two groups present no sign of narrowing. Galor [44] argued that this phenomenon was caused by differences in labor endowment.

In recent years, a great deal of empirical analysis has been made of the convergence of regional economic growth in China (Lin and Liu, [45]). Many scholars also applied the convergence method in other fields for empirical test. Zhang and Liu [46] studied the convergence of fiscal policies of 29 provinces in China during 1994-2005, arguing that tax revenue per capita, individual income tax per capita and other variables at provincial level in China converged. Those studies not only enriches the content of convergence, provides new analysis perspectives, but also gives insight into analysis of regional differences in social development in China.

Analysis of the convergence of the human development index has also attracted attention of foreign scholars. Noorbakhsh [47] studied differences in social development of developed and developing countries with data of 93 countries during 1975-2001, and analyzed the inequalities in social development among different countries and their dynamic changes. After making appropriate improvements, on the basis of studies of Noorbakhsh [47], we analyze the issue with panel data of 31 provinces in China during 1997-2006. 


\subsection{Convergence of the Human Development Index (HDI)}

As a comprehensive indicator of social development, the human development index, proposed by the United Nations in 1990, is a composite index of four indicators. Its components are to reflect three major dimensions of development: (1) longevity, represented by life expectancy at birth; (2) acquisition of knowledge, represented by a measure of educational achievement based on a weighted sum of adult literacy rate and gross enrolment ratio in primary school, middle school and university; (3) a decent standard of living, represented by the logarithm of real income per capita (purchasing power parity) Therefore, the HDI includes two non-income indices: the education index and life expectancy index. Whether the convergence hypothesis can be applied to those two indices?

Based on the assumptions of neo-classical growth model, convergence of economic growth lies in diminishing marginal returns on capital. Firstly, the assumption of diminishing marginal returns on capital can not only be applied to the income component of HDI (real income per capita), but also can be used to two other non-income components of HDI-education and life expectancy index. As two regions with different initial levels of development, an equal amount of investment in education and health will bring in different returns. The rates of return of investment in education and health decline with the increase of investment, so the region with low initial level of investment achieves a higher growth rate, and ultimately converges. Secondly, the concept of steady-state growth rate can also be applied to education and life expectancy. Compared with output and income in the neo-classical growth model, indicators of adult literacy rate, life expectancy and gross enrolment ratio are obtained at national (or provincial) level and corresponding upper bounds are defined. Therefore, the steady-state growth rates of these indicators are more homogeneous. What is more important is that for countries (regions) with low quality of life, it is more meaningful to have access to technologies related to education and health to improve the literacy rate, life expectancy and gross enrolment ratio and achieve their basic standard of living, rather than to obtain technologies to raise their productivity levels.

Based on the analysis above, we think that in the long run, underdeveloped regions with initially low levels of social development will have higher growth rates than those developed regions and eventually reach the steady state. In the next section, we will use panel data of 31 provinces in China from 1997 to 2006 to verify the convergence of HDI empirically. Compared with the cross-country study of Noorbakhsh [47], the use of data of different regions in one country can effectively avoid explanation for plenty of non-economic factors, which can be represented by dummy variables. For different provinces, there is no difference in these non-economic factors at the same time.

\section{Empirical Analysis of Regional Convergence of Social Development in China}

\subsection{Empirical Analysis of $\beta$ Convergence of HDI in China}

The $\beta$ convergence method is derived from the neo-classical growth model, that is, to examine the convergence of regional economic growth by measuring the $\beta$ convergence coefficient. Its economic implication is: if the economic growth rate of underdeveloped region is higher than that of the developed region, then per capita income (output) of underdeveloped region will eventually catch up with that of the developed region. The $\beta$ convergence coefficient refers to the speed of certain economic indicator of undeveloped region to catch up with that of the developed region. The $\beta$ convergence model of HDI proposed by Noorbakhsh [47] is as follows:

$$
\frac{1}{T} \log \left(\frac{h d i_{i t+T}}{h d i_{i t}}\right)=\alpha+\beta \log \left(h d i_{i t}\right)+\sum_{j=1}^{j k} \lambda_{i j} S_{i j}+\mu_{i t}, \text { for } k=0,1,2, \ldots, k
$$

where, $h d i_{i t}=\frac{H D I_{i t}}{H D I_{t}}$ is the proportion of HDI of region $i$ in the average of HDI of all regions. This standardized human development index can reflect changes in the relative positions of different provinces, thus to indicate true level of development $\left(h d i_{i, t}>1\right.$ means the development level of province 
$i$ in year $t$ exceeds the national average, and $h d i_{i, t}<1$ means the development level of province $i$ in year $t$ is lower than the national average). $\frac{1}{T} \log \left(\frac{h d i_{i t+T}}{h d i_{i t}}\right)$ represents the average annual growth rate of HDI of region $i$ from period $\mathrm{t}$ to $\mathrm{T}$. If $-1<\beta<0$, it means there exists $\beta$ convergence. It is equivalent to say that the growth rate of HDI is negatively related to the initial HDI level, and underdeveloped regions develop faster than developed regions. The closer $\beta$ approaches -1 , the faster the convergence speed is. The closer $\beta$ approaches 0 , the slower the converge speed is ( $\beta=0$ indicates no convergence; m means divergence). $S_{i j}$ indicates the $j$-th structural condition variable, and $\lambda_{i j}$ is the corresponding coefficient. When the structural condition variable changes, there are $\mathrm{k}$ different models. When $k=0$, there is no structural condition variable, and Equation (1) is the absolute $\beta$ convergence model.

According to the modeling framework of Noorbakhsh [47], we set $\mathrm{T}=2$ to examine the average annual growth rate of HDI every three years during 1997-2006 and eliminate the effects of short-term fluctuations during the economic cycle. We adopt the fixed effects model to estimate the convergence Equation (1). First of all, based on the economic theories embodied in the regression equation, there is a correlation between the individual effects of the regression equation and other explanatory variables. To set the individual effects fixed can be theoretically supported. Instead, the random effects assume that unobservable individual effects have no correlation with the explanatory variables in the regression equation, which is considered to be inappropriate in this model. In addition, from the perspective of econometrics, we also use the fixed effects and random effects to estimate the individual effects, and all Hausman test results are highly significant. That is, the fixed effects method is better than the random effects approach. Thus, only estimation results of fixed effects method are presented.

In the choice of main variables of the model, we choose control variables reflecting conditional convergence based on contribution of components of the human development index. The proportion of fixed asset investment in GDP (tzl) of certain province reflects the impacts on income index of HDI. The share of public expenditure on health and education in total GDP of one province (JW) represents the contribution to life expectancy index and education index, respectively. The proportion of investment in electric power infrastructure in fixed asset investment indicates the level of infrastructure (Data of HDI comes from Tian et al. (2008) [48]; data of fixed asset investment and expenditure on science, education, culture and hygiene is from "China Statistical Yearbook" during 1998-2007 [49]; data of investment in electric power infrastructure is derived from "China Electric Power Yearbook") [49]. We verify the $\beta$ convergence hypothesis of HDI through a series of models, including conditional and absolute convergence. Empirical results are shown in Table 1.

Table 1. $\beta$ convergence model of HDI.

\begin{tabular}{ccccc}
\hline model/variable & $\mathbf{1}$ & $\mathbf{2}$ & $\mathbf{3}$ & $\mathbf{4}$ \\
\hline Constant & $-0.0001(0.0002)$ & $0.0042(0.0012)^{* * *}$ & $0.0149(0.0045)^{* * *}$ & $0.0186(0.0046)^{* *}$ \\
\hline Ln(hdi) & $-0.1081(0.0198)^{* * *}$ & $-0.1213(0.0203)^{* * *}$ & $-0.1175(0.0198)^{* * *}$ & $-0.1344(0.0191)^{* * *}$ \\
\hline Ln(tzl) & & $0.0043(0.0012)^{* * *}$ & $0.0061(0.0014)^{* * *}$ & $0.0054(0.0014)^{* * *}$ \\
\hline Ln(jw) & & & $0.0061(0.0025)^{* *}$ & $0.0039(0.0027)^{*}$ \\
\hline Ln(dltz) & & & & $0.0032(0.0006)^{* * *}$ \\
\hline Adjusted $R^{2}$ & 0.5927 & 0.6813 & 0.6954 & 0.6990 \\
\hline F statistic & $12.5956^{* * *}$ & $17.4978^{* * *}$ & $18.0853^{* * *}$ & $17.8671^{* * *}$ \\
\hline
\end{tabular}

Note: Figures in parentheses are the standard deviations. ${ }^{* * *},{ }^{* *}, *$ means that results are statistically significant at $1 \%, 5 \%$ and $10 \%$ levels, respectively.

As is shown in Table 1, Model 1 reflects the absolute $\beta$ convergence. The coefficient of the variable $\ln \left(h d i_{i t}\right)$ is negative and significant at the $1 \%$ level, indicating clear tendency to convergence amongst provinces in the samples. However, the magnitude of the coefficient indicates very slow speed of convergence over the period. 
Model 2-4 introduces various control variables to reflect the conditional convergence hypothesis gradually. The neo-classical growth model emphasizes the role of capital investment in economic growth. When other variables are equal, in the long run, the higher the proportion of capital investment in GDP is, the more productive the effective labor is. Therefore, we introduce a variable into Model 2-proportion of capital investment in GDP (tzl) to reflect the effects on income component of HDI (real income per capita). As can be seen from Table 1, the coefficient of proportion of fixed assets investment is positive and significant at the $1 \%$ level, which is in accordance with the expectation of neo-classical growth theory. The coefficient of $\ln \left(h d i_{i t}\right)$ is negative and significant at the level of $1 \%$, and the absolute value of the coefficient in Model 2 is larger than that in Model 1, indicating that capital investment increases the speed of convergence from underdeveloped regions to developed regions. The new variable-proportion of public expenditure on education and health in GDP (JW) introduced into Model 3 on the basis of Model 2 reflects the effects on non-income components of HDI (education index and life expectancy index). The coefficient of this variable is positive and significant at the level of $5 \%$. However, the coefficient of $\ln \left(h d i_{i t}\right)$ is significantly negative, indicating the existence of conditional convergence.

Finally, we introduce the variable-share of electric power investment in fixed assets investment (dltz) into Model 4 to reflect the control variable of infrastructure. Energy is a prerequisite for meeting basic human needs. Suarez [50] believed that, in the initial stage, energy inputs play a significant role in promoting the increase of the human development index (HDI). Electricity power, an important secondary energy, is an important symbol of modern civilization. The supply and configuration of electric power infrastructure is a reflection of economic and social development. Therefore, on the basis of Model 3, the share of electricity power investment in fixed-asset investment (dltz) is introduced into Model 4. Results show that the coefficient of the variable is significantly positive at the $1 \%$ level. Meanwhile, $\overline{R^{2}}$ of the equation becomes larger, which means the electric power investment has a positive effect on social development. The coefficient of $\ln \left(h d i_{i t}\right)$ remains significantly negative and its absolute value is maximum in Model 4, indicating the fastest convergence speed.

Empirical analysis above provides support for the proposition of conditional $\beta$ convergence and weak absolute convergence of social development in China. In the models above, coefficients of $\ln \left(h d i_{i t}\right)$ are significantly negative, indicating that the results are robust. After control variables are introduced, the convergence speed becomes faster. As can be seen from the influencing factors of conditional convergence, the speed of regional convergence of social development is related with fixed assets investment, public expenditure on health and education as well as infrastructure investment. From the perspective of economic theories, due to diminishing marginal returns on capital, underdeveloped areas with less capital have larger margins of capital and higher rates of capital accumulation, thus to attract capital inflows. Increasing health and education investments in underdeveloped regions contributes to high-quality and healthy human capital for regional economic and social development. In addition, infrastructure is a prerequisite for economic growth and social development. Effective investment in electric power infrastructure is beneficial to transforming resource superiority of underdeveloped regions into economic growth, increasing tax revenues, improving employment and promoting the social development convergence.

\subsection{Empirical Analysis of $\sigma$ Convergence of Regional Human Development Index in China}

The so-called $\sigma$ convergence refers to: in the long run, countries or regions that deviate from the mean would converge to the steady state. The $\sigma$ convergence is a necessary but not sufficient condition for $\beta$ convergence. In the existing literature, empirical researches on $\sigma$ convergence generally focus on the standard deviation of a log transformed variable, whose implicit assumption is that for all countries (or regions), the steady-state levels and time trends of the examined variables are the same. Therefore, the $\sigma$ convergence of HDI indicates that as time goes by, the standard deviation of HDI 
of different countries (or regions) is decreasing, and that social development level shows a trend of convergence. Set $\sigma_{t}$ as standard deviation of $\log$ (hdi) in time $t$, namely:

$$
\sigma_{t}=\sqrt{\frac{\sum_{p=1}^{n}\left[\log \left(\mathrm{hdi}_{i t}\right)-\overline{\log \left(\mathrm{hdi}_{i t}\right)}\right]^{2}}{n-1}}
$$

where, $\mathrm{n}$ is the number of the provinces. In addition, Liu and Zhang [51] estimated the $\sigma$ convergence by calculating the coefficient of variation and Gini coefficient as a complement to the standard deviation method. Therefore, we use the abovementioned method to measure the $\sigma$ convergence of regional distribution of HDI in China during 1997-2006, as is shown in Table 2. The SD in Table 2 is the standard deviation of $\log (\mathrm{hdi})$. CV represents the coefficient of variation, which is the ratio of standard deviation to the mean of distribution, while the Gini coefficient (Gini) is a measure of dispersion amongst provinces (Here, calculation of the Gin coefficient does not take population into account. The simplified formula is: Gini $=\frac{1}{2 n^{2} \mu} \sum_{i=1}^{N} \sum_{j=1}^{N}\left|y_{i}-y_{j}\right|$, where, $n$ is the number of regions and $y_{i}$ is the HDI of region $i)$.

Table 2. Estimate of $\sigma$ convergence of HDI.

\begin{tabular}{cccccccc}
\hline Year & SD Log(hdi) & CV & Gini & Year & SD Log(hdi) & CV & Gini \\
\hline 1997 & 0.0941 & 0.0910 & 0.0488 & 2002 & 0.0751 & 0.0740 & 0.0407 \\
1998 & 0.0951 & 0.0915 & 0.0488 & 2003 & 0.0783 & 0.0760 & 0.0405 \\
1999 & 0.0918 & 0.0881 & 0.0468 & 2004 & 0.0682 & 0.0671 & 0.0364 \\
2000 & 0.0856 & 0.0829 & 0.0446 & 2005 & 0.0656 & 0.0644 & 0.0352 \\
2001 & 0.0813 & 0.0792 & 0.0427 & 2006 & 0.0649 & 0.0635 & 0.0344 \\
\hline
\end{tabular}

Obviously, as time goes on, the standard deviation (SD), coefficient of variation (CV) and Gini coefficient (Gini) become smaller. All measures show that social development of different regions in China converge at a certain speed. However, the pace of convergence seems to be a little slow, which is consistent with our previous results of $\beta$-convergence.

\section{Measurement of Population-Weighted Regional Inequality and Its Dynamic Changes}

The previous section focuses on validation for the convergence of social development in China. However, the abovementioned method of assessing the degree of convergence among different regions does not take into account the population of the provinces concerned. In addition, as convergence is basically about poor countries catching up with rich countries, Quah [31] believed that it is better to analyze the dynamic distribution of cross-regional economic development but not the convergence of individual economy to their own steady state. As can be seen from the literature on economic growth in recent years, this method has become one of the hot issues for scholars (Quah [31]; Morrisson [52]). Therefore, in this section, from the viewpoint of economic growth distribution, we investigate regional inequality of social development and its dynamic changes in China.

First of all, we use two methods to measure inequality - the Gini coefficient and Theil index, and take into account the population share of provinces. The Gini coefficient is a statistical indicator measuring the inequality of income in a country or region, whose range is [0,1]. Currently, there exist many formulas and algorithms for calculation and decomposition of Gini coefficient. Here we adopt the population-weighted Gini coefficient, which is calculated as follows:

$$
\text { Ginip }=\frac{1}{\mu} \sum_{i=1}^{N} \sum_{j=1}^{N} f\left(y_{i}\right) \mathrm{f}\left(\mathrm{y}_{j}\right)\left|y_{i}-y_{j}\right|
$$


where, $n$ is the number of regions; $y_{i}$ and is HDI of region $i ; f\left(y_{i}\right)$ represents the proportion of population of region $i$ in the total population; $\mu$ indicates the average of HDI of all regions. While the formula of Theil index is as follows:

$$
T=\sum_{i=1}^{N} Y_{i} \log \frac{Y_{i}}{X_{i}}
$$

where, $n$ is the number of regions, $Y_{i}$ and $X_{i}$ is HDI and the proportion of population of region $i$ in the total population, respectively. The Larger the Theil index is, the higher the regional inequality is; conversely, the smaller the Theil index is, the lower the inequality in social development is.

Most of the literature on decomposition results of Gini coefficient and Theil coefficient show that regional inequality in China is mainly from provincial inequality, and provincial inequality accounts for a small share (Yao and Zhang, [53]). Therefore, we mainly use these two methods to calculate the Gini coefficient and Theil index of provincial social development level in China. Results are shown in Table 3.

Table 3. Measurement of population-weighted inequality.

\begin{tabular}{ccc}
\hline Year & Gini coefficient P (country) & Theil index (country) \\
\hline 1998 & 0.0686 & 0.2841 \\
2000 & 0.0614 & 0.2813 \\
2002 & 0.0528 & 0.2844 \\
2004 & 0.0570 & 0.2816 \\
2006 & 0.0562 & 0.2746 \\
\hline
\end{tabular}

As can be seen from the results in Table 3, The Gini coefficients of HDI of different provinces of China show a trend of slight decline and weak convergence. The Theil index changes little. It rises slightly only in 2002, and declines little throughout the period, of which the overall trend is in line with the conclusion of weak convergence in the previous section.

Another way to analyze regional distribution of HDI is to study the degree of changes in distribution of different regions throughout the country over time. In most domestic studies, China is divided into Eastern, Central and Western regions. Regional economic policies are conducted according to the pattern of the three regions, which occupies an important position in China's classification system of economic zone. Therefore, this paper still adopts the abovementioned classification of the three regions (In this article, the Eastern China includes Beijing, Tianjin, Shanghai, Liaoning, Shandong, Jiangsu, Zhejiang, Fujian, Guangdong, Hainan, and Hebei; the Central China includes Anhui, Henan, Hubei, Hunan, Heilongjiang, Jilin, Shanxi and Jiangxi; the Western China includes Gansu, Tibet, Qinghai, Ningxia, Sichuan, Shanxi, Inner Mongolia, Xinjiang, Guangxi, Guizhou and Chongqing). Table 4 shows the regional composition of various quintiles of the distribution of HDI for all provinces during the sample period.

It shows that there is disparity of social development in the distribution of provinces in China. First, the second row of the table shows the distribution of provinces in various regions of China. The share of the number of provinces in Eastern, Central and Western China in the total country is $35.5 \%, 25.8 \%$ and $38.7 \%$, respectively. However, we find that, those provinces at the upper one-third percentile are dominated by the Eastern China, while provinces at the lower one-third percentile are dominated by the Western China. The overall picture for the dynamics of human development during the entire period (1997-2006) reveals little change for the most developed region (Eastern China), while the changes in the distribution between Central and Western China are more notable. 
Table 4. Changes in regional HDI distribution at different percentile levels (\%).

\begin{tabular}{cccccc}
\hline \multirow{2}{*}{1} & Eastern China & Central China & Western China & Total \\
\cline { 2 - 6 } \multirow{3}{*}{1997} & distribution & $\mathbf{3 5 . 5}$ & $\mathbf{2 5 . 8}$ & $\mathbf{3 8 . 7}$ & $\mathbf{1 0 0 . 0}$ \\
\hline \multirow{3}{*}{2001} & lower 1/3 & 0.0 & 10.0 & 90.0 & 100.0 \\
& Middle 1/3 & 18.2 & 54.5 & 27.3 & 100.0 \\
& Upper 1/3 & 90.0 & 10.0 & 0.0 & 100.0 \\
\hline \multirow{3}{*}{2006} & Lower 1/3 & 0.0 & 20.0 & 80.0 & 100.0 \\
& Middle 1/3 & 18.2 & 45.4 & 36.4 & 100.0 \\
& Upper 1/3 & 100.0 & 0.0 & 0.0 & 100.0 \\
& Lower 1/3 & 0.0 & 30.0 & 70.0 & 100.0 \\
& Middle 1/3 & 18.2 & 36.4 & 45.4 & 100.0 \\
& Upper 1/3 & 90.0 & 10.0 & 0.0 & 100.0 \\
\hline
\end{tabular}

In 1997, the vast majority of provinces at the upper one-third percentile of HDI are in Eastern China (Eastern China, 90\%; Central China, 10\%, respectively), whereas the number of provinces in Western and Eastern China accounts for $90 \%$ and $10 \%$ of total provinces at the lower one-third percentile, respectively. The HDI distribution changed in 2001, as opposed to 1997. The number of provinces in the Western and Eastern China accounts for $80 \%$ and $20 \%$ of total provinces at the lower one-third percentile, respectively. This is because after 1997, with the establishment of Chongqing municipality, location advantage of Chongqing played an important role, and its economic and social indicators improved substantially, leading the HDI of Chongqing Province to rise to the upper one-third percentile. While during this period, the ranking of HDI of Anhui Province in the whole country declined. For provinces at the upper one-third percentile, as the HDI of Heilongjiang province decreased, while the HDI of Hainan Province increased, provinces at the upper one-third percentile are all in Eastern China. Since 2006, the number of provinces in Western and Eastern China have even accounted for $70 \%$ and $30 \%$ of total provinces at the lower one-third percentile of HDI, respectively. The reason is that Inner Mongolia in Western China has developed rapidly in recent years, while Hunan and other provinces in Central China have declined. The share of provinces in Central China provinces in total provinces at the middle one-third percentile decreased from $54.5 \%$ in 1997 to $36.4 \%$ in 2006 , while the share of provinces in the western part increased from $27.3 \%$ to $45.4 \%$. In terms of changes in social development in China, during 1997-2006, with the implementation of the Western Development Strategy, compared to provinces in Central China, provinces in Western China developed fast, and the gap between Central and Western China was narrowed. There is a trend of "convergence club" in Central and Western China. It seems that original poor regions (Western China) have remain stable while provinces in Central China which are relatively developed regions have declined.

In order to further study dynamic changes in regional inequality, we need to find out how countries change position over time at different intervals (taking population into account).This method has been often used in researches on changes in income distribution among different countries in recent years. Therefore, we use it to divide the HDI in each sub-period into four intervals according to the degree of deviation from the sample mean, and calculate corresponding dynamic changes of all sample points at different intervals. Table 5 shows that during each sub-period, the population share changes at different HDI intervals. The "population share" in the rows and columns of the table represents the population share at the beginning and the end of sample period. Comparing rows with columns in the matrix, we can analyze changes in regional inequality during each sample period. The retention rate represents the population share that does not change during the examined sample period while the upward rate and downward rate is the population share that moves to regions with higher and lower HDI, respectively.

As is shown in Table 5, during 1997-2001, regional distribution of HDI did not change obviously. $86.4 \%$ of population still stayed in the original interval, and the upward rate and downward rate was only 3.3\%, $10.3 \%$, respectively, which was the result of rise of position of Qinghai and Shanxi province 
(moving from the interval less than $5 / 6$ to the interval $(5 / 6,1)$ and decrease of position of Guangxi and Hunan (moving from the interval $(1,7 / 6)$ to the interval $(5 / 6,1)$. In addition, developed provinces in Eastern China converged to the interval $(1,7 / 6)$. As a result, the population share in the interval more than $7 / 6$ decreased from $1.2 \%$ in 1997 to $\%$ in 2001. During 2001-2006, the retention rate still kept high $(82.1 \%)$, while both the upward rate and upward rate increased to $10.3 \%$ and $7.6 \%$, respectively. During this period, due to accelerated development of Inner Mongolia and Chongqing, their HDI rose from the interval $(5 / 6,1)$ to the interval $(1,7 / 6)$. In addition, development of Tibet province made the population share in the interval less than $5 / 6$ declined to 0 . Those declined provinces are Hubei and Shanxi.

Table 5. Transfer matrix of HDI based on the population share and corresponding rates of change.

\begin{tabular}{|c|c|c|c|c|c|c|}
\hline \multirow{2}{*}{$\begin{array}{l}\text { Intervals with HDI } \\
\text { deviating from mean at } \\
\text { the end of sample period }\end{array}$} & \multicolumn{4}{|c|}{$\begin{array}{l}\text { Intervals with HDI deviating from mean } \\
\text { at the beginning of sample period }\end{array}$} & \multirow{2}{*}{$\begin{array}{l}\text { Population } \\
\text { share }\end{array}$} & \multirow{2}{*}{$\begin{array}{l}\text { Rate of } \\
\text { change }\end{array}$} \\
\hline & more than $7 / 6$ & $(1,7 / 6)$ & $(5 / 6,1)$ & Less than $5 / 6$ & & \\
\hline \multicolumn{7}{|c|}{ 1997-2001 } \\
\hline more than $7 / 6$ & 0.0 & 0.0 & 0.0 & 0.0 & 0.0 & \\
\hline$(1,7 / 6)$ & 100.0 & 85.1 & 7.8 & 0.0 & 56.3 & \\
\hline$(5 / 6,1)$ & 0.0 & 14.9 & 92.2 & 33.3 & 43.5 & \\
\hline Less than $5 / 6$ & 0.0 & 0.0 & 0.0 & 66.7 & 0.2 & \\
\hline Population share & 1.2 & 61 & 37.2 & 0.6 & 100.0 & \\
\hline Retention rate & & & & & & 86.4 \\
\hline Upward rate & & & & & & 3.3 \\
\hline Downward rate & & & & & & 10.3 \\
\hline \multicolumn{7}{|c|}{ 2001-2006 } \\
\hline more than $7 / 6$ & 0.0 & 0.0 & 0.0 & 0.0 & 0.0 & \\
\hline$(1,7 / 6)$ & 0.0 & 86.5 & 23.3 & 0.0 & 60.2 & \\
\hline$(5 / 6,1)$ & 0.0 & 13.5 & 76.7 & 100.0 & 39.8 & \\
\hline Less than $5 / 6$ & 0.0 & 0.0 & 0.0 & 0.0 & 0.0 & \\
\hline Population share & 0.0 & 56.3 & 43.5 & 0.2 & 100.0 & \\
\hline Retention rate & & & & & & 82.1 \\
\hline Upward rate & & & & & & 10.3 \\
\hline Downward rate & & & & & & 7.6 \\
\hline \multicolumn{7}{|c|}{ 1997-2006 } \\
\hline more than $7 / 6$ & 0.0 & 0.0 & 0.0 & 0.0 & 0.0 & \\
\hline$(1,7 / 6)$ & 100.0 & 77.3 & 57.5 & 0.0 & 60.2 & \\
\hline$(5 / 6,1)$ & 0.0 & 22.7 & 42.5 & 100.0 & 39.8 & \\
\hline Less than $5 / 6$ & 0.0 & 0.0 & 0.0 & 0.0 & 0.0 & \\
\hline Population share & 1.2 & 61 & 37.2 & 0.6 & 100.0 & \\
\hline Retention rate & & & & & & 74.1 \\
\hline Upward rate & & & & & & 10.8 \\
\hline Downward rate & & & & & & 15.1 \\
\hline
\end{tabular}

The last part of Table 5 shows dynamic changes in distribution of HDI during the examined sample period (1997-2006). Although the retention rate was high (74.1\%), but the upward or downward trend was obvious. The upward and downward rate was $10.8 \%$ and $15.1 \%$, respectively. We find that developed provinces which originally concentrated in the interval more than $7 / 6$ moved to the interval $(1,7 / 6)$, while underdeveloped provinces moved from the interval less than $5 / 6$ to the interval $(5 / 6,1)$. What is more important is that during this period, rapid development of some provinces in Western China contributed to rise of their positions, while provinces in Central China developed slowly, leading to the gap between provinces in central and western narrowed. Therefore, in the long run, regional distribution of social development in China evolves from the "solo peak" to "twin peaks", and shows a trend of "twin-peak convergence". That is, coastal provinces, which are in Eastern China, converge to the rich ones, while inland provinces which are in Western and Central China converge to the poor ones.

The main reasons for this phenomenon are: from the reform and opening up to the early 1990s, China gave priority to development of coastal regions, which are in Eastern China. Introduction of capital and talents, as well as the geographical advantage of coastal regions exacerbated the gap 
between coastal and inland regions. After 2000, the central government implemented the Western Development Strategy, and significantly increased investment in the construction of Western China. Provinces in Western China such as Chongqing and Inner Mongolia developed much. Therefore, as the Eastern China rapidly developed and Western China experienced considerable progress, the Central China was in the shade and lagged behind, giving rise to the so-called "central downfall".

\section{Conclusions and Policy Implications}

By applying the theory of convergence and concept of inequality to study the evolution of social development, we analyze regional inequality in social development in China both theoretically and empirically .First of all, empirical results of methods of $\beta$ and $\sigma$ convergence show evidence of weak absolute convergence and conditional convergence of provincial human development. Results of various models are robust and remain the same. Test results of $\sigma$ convergence are in line with those for $\beta$-convergence. Meanwhile, we find fixed-asset investment, public expenditure on education and health and infrastructure construction have positive effects on social development.

When the population of provinces are taken into account, the results show that the change of Gini coefficient and Theil index is small in spite of the downward trend. Furthermore, using the method of distribution dynamics to analyze dynamic changes and the degree of changes in social development in different provinces, we find that the distribution of provincial social development in China has a tendency to converge as "twin peaks". That is, provinces of Eastern China converge to the rich ones, while the West and Central China converge to the poor ones, and the Central China was in the shade and lagged behind. Therefore, the "rise of Central China" plan is necessary because it can play an important role in promoting effective link between developed Eastern China and underdeveloped Western China, which is of great significance in promoting balanced development among regions and sustainable development of macro economy.

To promote the "rise of central China", the existing "three bases, one hub" should be strongly highlighted and developed. It enhances industrial level, promotes the industrialization and urbanization and plays an active role in connecting the Eastern and Western China. First of all, the central China is rich in fertile land resources. As one of China's main grain produce areas, it should focus on food production, agricultural structure adjustment and agriculture industrialization. Secondly, in terms of energy and raw materials, Shanxi, Henan, Hubei, Anhui and other places have abundant coal resources. In accordance with the principles of optimized layout, efficient utilization, safety and environmental protection, it is necessary to consolidate and enhance the role of Central China as an energy and raw material base, accelerate power grid construction, and vigorously develop the deep processing of raw materials. Thirdly, with regards to equipment manufacturing, Wuhan, Changsha, Zhuzhou, Zhengzhou and other old industrial bases should be brought into full play, to promote independent innovation, accelerate the development of high-tech industries, and enhance the overall strength of equipment manufacturing industry. Finally, advantages of transport hubs in the Central China should be made full use, in order to optimize the allocation of transport resources, accelerate the construction of railway networks and power grids, perfect the road network, and improve the capacity of water and pipeline transport. Implementing the "Rise of Central China" strategy and promote economic and social development in Central China is of great significance to promote the balanced development between regions.

Acknowledgments: This paper is supported by the Fundamental Research Funds for the Central Universities (No. 20720151039) and the National Natural Science Foundation of China (No.71203186).

Author Contributions: Yang, F. constructed econometric models, performed all calculations and wrote most of the paper. Pan, S.Y. collected data on HDI and wrote the literature review. Yao, X. proposed research ideas, analyzed research results and offered policy suggestions.

Conflicts of Interest: The authors declare no conflict of interest. 


\section{References}

1. United Nations Development Programme. Human Development Report; Hoechstetter Printing: Pittsburgh, PA, USA, 2005.

2. Mikkelson, G.M. Growth Is the Problem; Equality Is the Solution. Sustainability 2013, 5, 432-439. [CrossRef]

3. Li, S.T.; Hou, Y.Z.; Feng, J.; He, J.W.; Xuan, X.W. The Past, the Present and the Future of the Regional Disparity in China. J. Reform 2004, 5, 6-18. (In Chinese).

4. Qin, C.L.; Luo, Q. A Study on the Regional Disparities of Human Development in China. J. Econ. Surv. 2004, 6, 49-51. (In Chinese)

5. Song, H.Y.; Ma, Y.L. Measuring Rural-Urban Disparity in China by Human Development Index Method. Econ. Res. J. 2004, 11, 4-15. (In Chinese)

6. Grimm, M.A. Human Development Index by Income Groups. World Dev. 2008, 36, 2527-2546. [CrossRef]

7. Harttgen, K.; Klasen, S. A Household-Based Human Development Index. World Dev. 2012, 40, 878-899.

8. Eric, N. The Human Development Index and Sustainability-A Constructive Proposal. Ecol. Econ. 2001, 39, 101-114.

9. Felice, E.; Vasta, M. Passive Modernization? Social Indicators and Human Development in Italy's Regions (1871-2009). Eur. Rev. Econ. Hist. 2015, 19, 44-66. [CrossRef]

10. Bravo, G. The Human Sustainable Development Index: New calculations and a first critical analysis. Ecol. Indic. 2014, 37, 145-150. [CrossRef]

11. Hou, J.; Walsh, P.P.; Zhang, J. The dynamics of Human Development Index. Soc. Sci. J. 2014. [CrossRef]

12. Ravallion, M. Troubling tradeoffs in the Human Development Index. J. Dev. Econ. 2012, 99, $201-209$. [CrossRef]

13. Samuel, C.D.; Pedro, C.H.; Rodrigo, S.R.; Harold, W.K. Worldwide prevalence of physical inactivity and its association with human development index in 76 countries. Prev. Med. 2011, 53, $24-28$.

14. Li, X.L.; Yi, C.; Chao, H.Y.; You, M.L.; Juan, Y. National HIV/AIDS mortality, prevalence, and incidence rates are associated with the Human Development Index. Am. J. Infect. Control 2014, 42, 1044-1048.

15. Yekeen, A.S. Application of human development index to measurement of deprivations among urban households in Minna, Nigeria. Habitat Int. 2008, 32, 384-398.

16. Freddie, B.; Ahmedin, J.; Nathan, G.; Jacques, F.; David, F. Global cancer transitions according to the Human Development Index (2008-2030): A population-based study. Lancet Oncol. 2012, 13, 790-801.

17. Nadia, S.O. Energy consumption and human development: Evidence from a panel cointegration and error correction model. Energy 2013, 63, 28-41.

18. Yang, Y.H.; Hu, A.G.; Zhang, N. An Alternative to Human Development Index with Principal Component Analysis. Econ. Res. J. 2005, 7, 4-17. (In Chinese)

19. Yang, Y.H.; Hu, A.G.; Zhang, N. The Regional Disparities and Imbalance of China's Human Development: A Historical Perspective of "One China, Four worlds". China Econ. Q. 2006, 5, 803-816. (In Chinese)

20. Hu, D.P. Trade, rural-urban migration, and regional income disparity in developing countries: A spatial general equilibrium model inspired by the case of China. Reg. Sci. Urban Econ. 2002, 32, 311-338. [CrossRef]

21. Qin, D.; Cagas, M.A.; Ducanes, G.; He, X.H.; Liu, R.; Liu, S.G. Effects of income inequality on China's economic growth. J. Policy Model. 2009, 31, 69-86. [CrossRef]

22. Gustafsson, B.; Sai, D. Rank, income and income inequality in urban China. China Econ. Rev. 2009, 20, 497-507. [CrossRef]

23. Appleton, S.; Song, L.; Xia, Q.J. Understanding Urban Wage Inequality in China 1988-2008: Evidence from Quantile Analysis. World Dev. 2014, 62, 1-13. [CrossRef]

24. Naranpanawa, A.; Arora, R. Does Trade Liberalization Promote Regional Disparities? Evidence from a Multiregional CGE Model of India. World Dev. 2014, 64, 339-349. [CrossRef]

25. Duan, P.Z. Influence of China's Population Mobility on the Change of Regional Disparity since 1978. China Popul. Resour. Environ. 2008, 18, 27-33.

26. Chirila, V.; Chirila, C. The impact of economic and financial crisis on the regional disparities in Romania and European Union. Proced. Soc. Behav. Sci. 2014, 109, 502-506. [CrossRef]

27. Song, S.F.; Chu, G.S.F.; Chao, R.Q. Intercity regional disparity in China. China Econ. Rev. 2000, 11, $246-261$. [CrossRef] 
28. Liu, X.Y.; Wang, X.Q.; Whalley, J.; Xin, X. Technological change and China's regional disparities-A calibrated equilibrium analysis. Econ. Model. 2011, 28, 582-588. [CrossRef]

29. Barro, R.J.; Sala-i-Martin, X. Convergence. J. Polit. Econ. 1992, 100, 223-251. [CrossRef]

30. Mankiw, N.G.; Romer, D.; Weil, D.N. A Contribution to the Empirics of Economic Growth. Q. J. Econ. 1992, 107, 407-437. [CrossRef]

31. Quah, D.T. Twin Peaks: Growth and Convergence in Models of Distribution Dynamics. Econ. J. 1996, 106, 1045-1055. [CrossRef]

32. Sala-i-Martin, X. The Disturbing "Rise" of Global Income Inequality. Natl. Bur. Econ. Res. 2002. Available online: http:/ / www.nber.org/papers/w8904.pdf (accessed on 25 January 2016).

33. Cristina, M.D. Saferational approach to a valid sustainable development. Proced. Econ. Financ. 2014, 8, 497-504. [CrossRef]

34. Cornescu, V.; Adam, R. Considerations regarding the role of indicators used in the analysis and assessment of sustainable development in the EU. Proced. Econ. Financ. 2014, 8, 10-16. [CrossRef]

35. Nuzir, F.A.; Dewancker, B.J. Understanding the role of education facilities in sustainable urban development: A case study of KSRP, Kitakyushu, Japan. Proced. Environ. Sci. 2014, 20, 632-641. [CrossRef]

36. Radjiyev, A.; Qiu, H.; Xiong, D.P.; Nam, K. Ergonomics and sustainable development in the past two decades (1992e2011): Research trends and how ergonomics can contribute to sustainable development. Appl. Ergon. 2015, 46, 67-75. [CrossRef] [PubMed]

37. Bolcárová, P.; Kološta, S. Assessment of sustainable development in the EU 27 using aggregated SD index. Ecol. Indic. 2014, 48, 699-705. [CrossRef]

38. Chansarn, S. The Evaluation of the Sustainable Human Development: A Cross-Country Analysis Employing Slack-Based DEA. Proced. Environ. Sci. 2014, 20, 3-11. [CrossRef]

39. Elizabeth, A.S. The Tragedy of Maldistribution: Climate, Sustainability, and Equity. Sustainability 2012, 4, 394-411.

40. Qin, T.B. Challenges for Sustainable Development and Its Legal Response in China: A Perspective for Social Transformation. Sustainability 2014, 6, 5075-5106. [CrossRef]

41. Corina, R.; Rita, T.; Gratiela, B.; Madela, A.; Cristian, A.; Diana, C.T. Sustainable Development in Maramures County. Sustainability 2015, 7, 7622-7643.

42. Barro, R.J. Economic Growth in a cross section of countries. Q. J. Econ. 1991, 106, 407-443. [CrossRef]

43. Barro, R.J.; Sala-i-Martin, X. Economic Growth; McGraw Hill: New York, NY, USA, 1995.

44. Galor, O. Convergence? Inferences from Theoretical Models. Econ. J. 1996, 106, 1056-1069. [CrossRef]

45. Lin, Y.F.; Liu, M.X. Growth Convergence and Income Distribution in China. J. World Econ. 2003, 8, 3-14. (In Chinese)

46. Zhang, Y.L.; Liu, R. Analysis of China's Provincial Fiscal Policy Convergence: A Demonstration on Spatial Econometric Model. J. Cent. Univ. Financ. Econ. 2008, 4, 19-23. (In Chinese)

47. Noorbakhsh, F. International Convergence or Higher Inequality in Human Development? Evidence for 1975 to 2002. Available online: https:/ / www.econstor.eu/dspace/bitstream/10419/63439/1/510833616.pdf (accessed on 25 January 2016).

48. Tian, H.; Sun, J.P.; Zhu, Y.M. Comprehensive Measurement and Analysis for local Economic and Social Development-A Research Based on HDI. Econ. Manag. 2008, 2, 69-76. (In Chinese).

49. National Bureau of Statistics of the People's Republic of China. China Statistical Yearbook; China Statistical Publishing House: Beijing, China, 1998-2014. (In Chinese)

50. Suarez, C.E. Human Development and Energy: A View from the Developing Countries. In Energy for Survival and Development; Chagas, C., Colombo, U., Eds.; Ex Aedibvs Academicis in Civitate Vaticana: Vaticana City, Vaticana, 1996; pp. 93-116. Available online: http://www.casinapioiv.va/content/dam/ accademia/pdf/sv57pas.pdf (accessed on 25 January 2016).

51. Liu, S.C.; Zhang, X.J. The Features of China's Sustained High Growth and the Decline of Regional Economic Disparity. Econ. Res. J. 2007, 10, 17-31. (In Chinese) 
52. Bourguignon, F.; Morrisson, C. Inequality among World Citizens: 1820-1992. Am. Econ. Rev. 2002, 92, 727-744. [CrossRef]

53. Yao, S.J.; Zhang, Z.Y. On regional inequality and diverging clubs: A case study of contemporary China. J. Comp. Econ. 2001, 29, 466-484. [CrossRef]

(c) 2016 by the authors; licensee MDPI, Basel, Switzerland. This article is an open access article distributed under the terms and conditions of the Creative Commons by Attribution (CC-BY) license (http:/ / creativecommons.org/licenses/by/4.0/). 